\title{
Modeling for control of run-of-river power plant Gronvollfoss
}

\author{
Liubomyr Vytvytskyi $^{1} \quad$ Roshan Sharma $^{1} \quad$ Ingunn Granstrøm ${ }^{2} \quad$ Bernt Lie $^{1}$ \\ ${ }^{1}$ Faculty of Technology, Telemark University College, Norway, \{124022, roshan.sharma, \\ Bernt.Lie\} ahit.no \\ ${ }^{2}$ Skagerak Kraft AS, Norway, Ingunn. Granstromeskagerakenergi.no
}

\begin{abstract}
Design of optimal operation and control of a run-of-river hydro power plant depends on good models for the elements of the plant. River reaches are often considered to be shallow channels with free surface flow. A typical model for such reaches thus use the Saint Venant model, which is a $1 \mathrm{D}$ model based on the mass and momentum balances. This combination of free surface and momentum balance makes the problem numerically challenging to solve.

Here, the finite volume method with staggered grid is used to illustrate the dynamics of the river upstream from the Grønvollfoss run-of-river power plant in Telemark, Norway, operated by Skagerak Energi. A model of the same river in the Grønvollfoss power plant has been studied previously, but here the geometry of the river is changed due to new information from Skagerak Energi. The numerical scheme for solving the model has been further developed.

In addition, the behavior of the dynamic model is compared to data from experiments, carried out on the Grønvollfoss run-of-river power plant. The essence of the experiments is to consider the time taken from an increase in the input volumetric flow, to a measured change in level in front of the dam at Grønvollfoss.

The model is manually tuned by changing the Strickler friction factor, the river length and the type of river slope/width (constant/varying) in order to fit the water level ahead of the Grønvollfoss dam from experimental data. Least squares model fitting is also used for the model with the constant slope and width of the river and this model shows good fitting after the manual tuning.

The results of the improved model (numerically, tuned to experiments), is a model that can be further used for control synthesis and analysis.
\end{abstract}

Keywords: Run-of-river hydropower, Saint Venant Equations, Modeling, Simulation.

\footnotetext{
${ }^{1}$ https://www.regjeringen.no/nb/tema/energi/fornybarenergi/fornybar-energiproduksjon-i-norge/id2343462/

${ }^{2}$ https://www.regjeringen.no/nb/tema/klima-ogmiljo/naturmangfold/innsiktsartikler-
}

\section{Introduction}

\subsection{Background}

There are in total operating over 1500 hydro power plants in Norway today, with a total capacity of more than $28 \mathrm{GW}$. Water power plants have an annual production of $129 \mathrm{TWh}$ in 2013, which constitutes some $96 \%$ of the production of electricity ${ }^{1}$. Most hydropower production comes from large hydropower plants with water reservoirs. Small hydropower plants is a generic term for plants that have small production capacity. There are in total operating over 1100 such smaller hydropower plants in Norway today and production from these accounts for about 7\% of the total hydropower production ${ }^{2}$.

Skagerak Energi is operating two run-of-river hydro power plants in river Tinnelva flowing out of lake Tinnsjøen in Eastern Telemark. The uppermost, Årlifoss, has a $16.2 \mathrm{~m}$ water fall, and provides inlet flow to the pondage of Grønvollfoss; the Grønvollfoss power plant is in question here. Grønvollfoss is situated $5 \mathrm{~km}$ downstream from Årlifoss, and has a water fall of 22.6 $\mathrm{m}$. The installed power in Grønvollfoss is 2x16MW (i.e. two turbines), and the average annual production is 172GWh.

It is of interest to keep the level in front of the dam in Grønvollfoss as high as possible to give as high a turbine pressure as possible to maximize power production. In addition, the dam level should be as constant as possible to avoid variation in production, and loss of water flowing over the dam. It is important to control the level/production because both the production and the inflow of water from upstream disturbs/upsets the level.

\subsection{Previous work}

The dynamic model for such run-of-river system has an important role in control and optimization. In a previous paper (Lie et al., 2013), a model for the Grønvollfoss power plant has been developed using the Saint-Venant equations and the staggered grid scheme. Discretization

naturmangfold/fornybar-energiproduksjon-inorge/id2076808/?regj_oss $=20$ 
of the Saint-Venant equations using the staggered grid scheme has been studied in Farina et al. (2011). The Quick and Superbee algorithms are more complex, but better algorithms for solving the Saint-Venant equations (Johansen et al., 2012a). Even better are adaptive WENO schemes (Johansen et al., 2015). In Xu et al. (2012), the problem of estimating the levels of three cascaded river reaches by using the Saint-Venant model has been described. Large rivers with several run-ofriver plants constitute large scale control and optimization problems; the application of e.g. Model Predictive Control has recently been studied for such systems (De Schutter et al., 2011).

\subsection{Overview of paper}

In this work, the geometry of the system has been substantially updated from that of Lie et al. (2013), and the resulting model has been compared to experiments on the system. The paper is structured as follows: Section 2 consists of a system description of the run-ofriver power plant. Section 3 describes formulation of the model with basic simulations for verification. The experiments from the power plant and their application for validation of the model are provided in Section 4. Conclusions are drawn in Section 5.

\section{System description}

A typical view of run-of-river power plant is presented in Figure 1. This type of hydro power plant has high flow rate, which passes through the turbine and spins the rotor. The turbine transfers the kinetic energy from water to rotational mechanical power, which then will be transferred to electric power in the generator.
After this the water returns to the river via a short tailrace

The Grønvollfoss power plant is situated in the river Tinnelva and is the second power plant in this river. That is why this power plant does not have a dedicated reservoir, but instead uses the outlet flow from the Årlifoss power plant as input; Årlifoss is situated upstream the river.

\subsection{Functional description}

For this run-of-river system, there are some inputs (control inputs, disturbances) and outputs (measured and performance (quality) outputs), which can affect and describe the functionality, as shown in Figure 2. The control inputs could be the outlet flow rate through the turbine $\dot{V}_{\text {out }}$ and possibly the flood gate opening at Grønvollfoss power plant. Also flow from the Årlifoss power plant, which is inlet flow rate $\dot{V}_{i n}$, can be assumed as control input if both plants are considered as one unit. However, this flow can also be a disturbance if the Grønvollfoss power plant is considered independently. Measured outputs can e.g. be the power production in the Grønvollfoss power plant, the level ahead of the Grønvollfoss dam, and also any other level measured in the river/dam between Årlifoss and Grønvollfoss, e.g. the level exactly after Årlifoss power plant. The power production can also be considered a performance output, which will show the result of one of the main goals: production maximization. The variation of the level ahead of the Grønvollfoss dam can be a performance output, because this level should be as constant as possible to avoid variation in production, which is also the main goal of the control challenge.

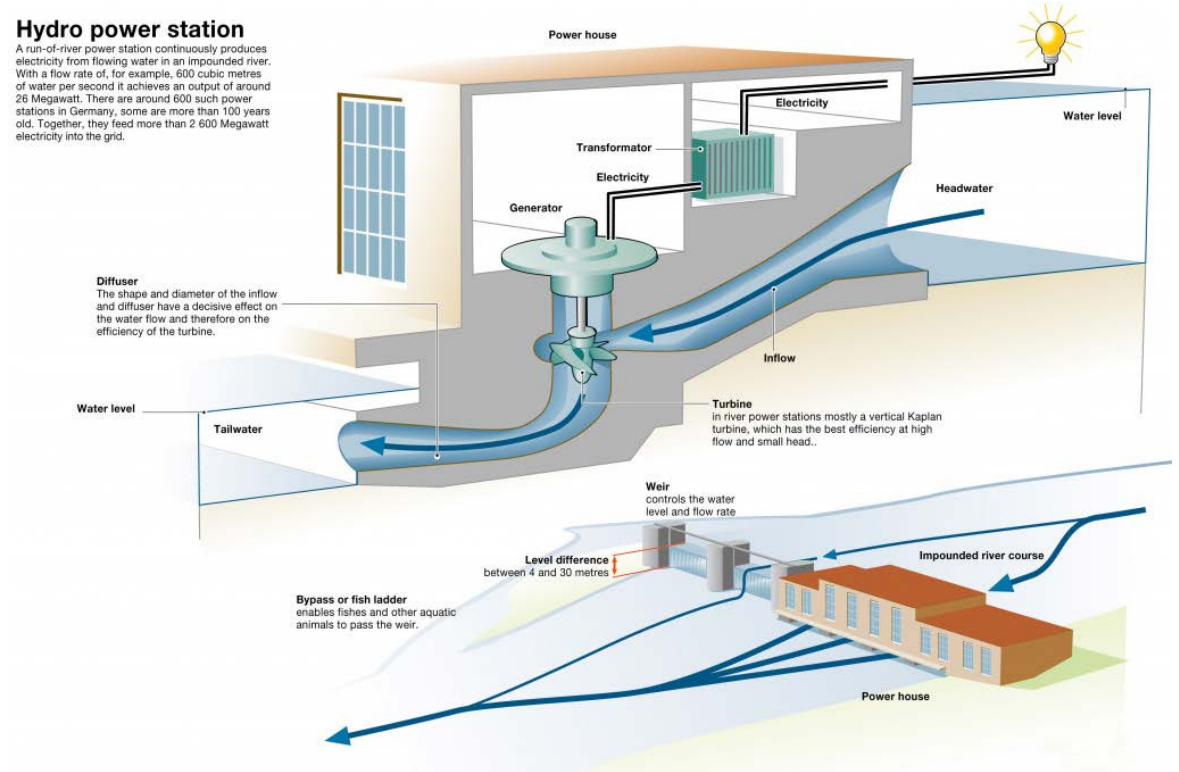

Figure 1. Run-of-river power plant ${ }^{3}$.

\footnotetext{
${ }^{3}$ http://www.commercialrenewableenergy.co.uk/hydropower/
} 


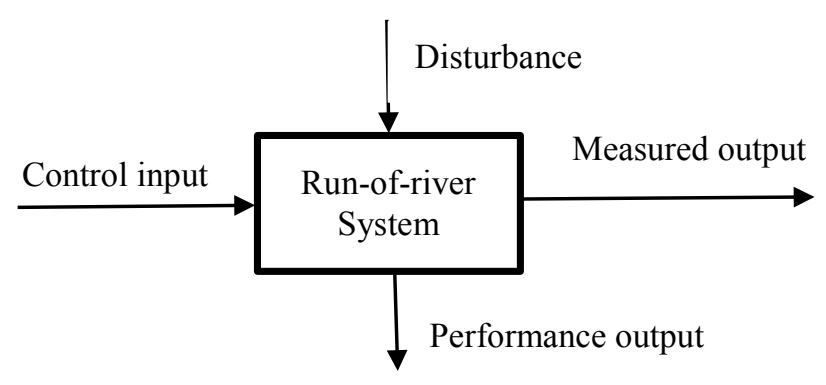

Figure 2. Functional description of run-of-river system.

Here, the Grønvollfoss power plant is chosen to be considered as an independent unit. The control inputs are therefore the outlet flow rate through the turbine $\dot{V}_{\text {out }}$ and the flood gate opening at Grønvollfoss power plant; the disturbance consists of inlet flow rate $\dot{V}_{i n}$. The power production in the Grønvollfoss power plant, and the level ahead of the Grønvollfoss dam is measured.

\subsection{System description}

The following information about the system is provided by Skagerak Energi and maps on the Internet. All of the provided parameters are approximations. The water level before the Grønvollfoss dam is around 19 meters above the river bed (level of riverbed in this place is 125.5 m.a.s.1. ${ }^{4},{ }^{5}$ and level of water is thus 144.5 m.a.s.1. ${ }^{6}$ ). There is also information about the level of the river surface (145.7 m.a.s.1.) and riverbed (143 m.a.s.1.) exactly after the Årlifoss power plant. In this case, the height difference between the two power plants (Årlifoss and Grønvollfoss) is around 17.5 meters. There is also information about the length of the river between the two power plants, $L=5$ kilometers, and the width of the river is on average $w=166 \mathrm{~m}$, which is found from the known length and surface area of the river, which is equal $0.83 \mathrm{~km}^{2}$ (this area is provided by Skagerak Energi). We will consider two cases: one with constant width and slope of the river, and another case where both the river width and the river slope may vary. In the first case of constant width and slope, the slope is given by Figure 3, and the width is given to be $w=166$ $\mathrm{m}$.

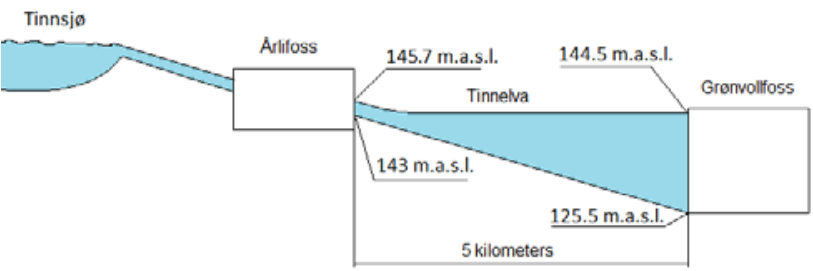

Figure 3. The schematic view of river geometric.

\footnotetext{
${ }^{4}$ Meters above sea level

${ }^{5} \mathrm{http}$ ://gis3.nve.no/nivellement/220.pdf The map of river from 1924, when the power plants have not been built and which shows the water level at that time.
}

In the second case, we allow both the river width and the river slope to vary. Because on maps of the river, the width is simplified as is shown in Figure 4.

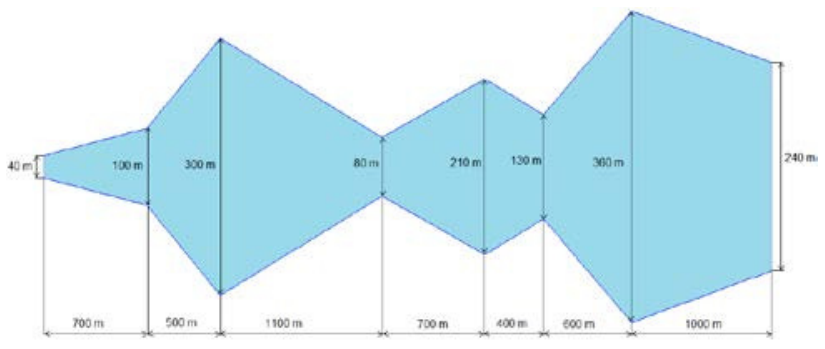

Figure 4. The schematic view of the width variation.

In reality, the slope of the river also varies along the river. For this work, the river map from year 1924 has been studied and then the slope is approximated as shown in Figure 5. For the first part of the river reach with length $L_{l}=2500 \mathrm{~m}$, the height drop is $H_{l}=7 \mathrm{~m}$, with slope angle $\theta_{1}=\sin ^{-1}\left(H_{1} / L_{1}\right)$. Then, for the next part, the slope changes the angle with the length $L_{2}=500 \mathrm{~m}$ and the height drop $H_{2}=6.5 \mathrm{~m}$, to $\theta_{2}=\sin ^{-1}\left(H_{2} / L_{2}\right)$. Finally, for the last part with length $L_{3}=2000 \mathrm{~m}$, the height drop $H_{3}=4 \mathrm{~m}$, and the slope angle of slope $\theta_{3}=\sin ^{-1}\left(H_{3} / L_{3}\right)$.

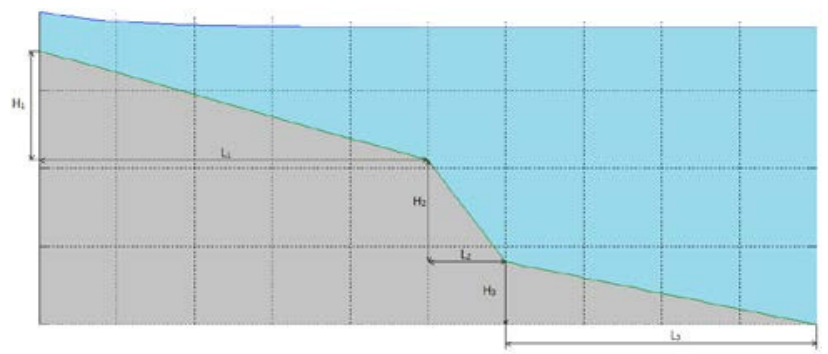

Figure 5. The schematic view of river slope.

\subsection{Experiment description}

To check and improve accuracy of the run-of-river model, the model will be validated and tuned against experiments on the Grønvollfoss power plant. Only one experiment was permitted.

This experiment consists in changing the inlet flow rate to the system $\dot{V}_{i n}$ for some time, and measuring the change of the level in front of the Grønvollfoss dam and also the time for which changes in inlet flow rate will start to influence the level in front of the dam.

The experiment table with all values for experiment is in Table 1.

It should be noted that the water level ahead of the Grønvollfoss dam was decreased by $15 \mathrm{~cm}$ before the experiment (to 144.35 m.a.s.1.) to avoid overflow the

http://atlas.nve.no/SilverlightViewer/?Viewer=NVEAtlas 
dam after increasing the inlet flow rate. In addition, the inlet volumetric flow rate is controlled by increasing or decreasing power production, thus the values of the flow rates are approximations. There is also information that the water level ahead of the Grønvollfoss power plant is measured by a sensor and logged every $5 \mathrm{~s}$. These results are filtered and are defined as a moving average of 300 values every $100 \mathrm{~ms}$ (the average of levels during last $30 \mathrm{~s})$.

Table 1. Experiment table.

\begin{tabular}{|l|l|l|l|}
\hline $\begin{array}{l}\text { Inlet } \\
\text { volumetric } \\
\text { flow rate, } \\
\mathrm{m}^{3} / \mathrm{s}\end{array}$ & $\begin{array}{l}\text { Outlet } \\
\text { volumetric } \\
\text { flow rate, } \\
\mathrm{m}^{3} / \mathrm{s}\end{array}$ & $\begin{array}{l}\text { Time } \\
\text { interval } \\
\text { for } \\
\text { changing, } \\
\text { min }\end{array}$ & $\begin{array}{l}\text { Initial level } \\
\text { ahead of the } \\
\text { dam, m.a.s.l }\end{array}$ \\
\hline $120-160-120$ & 120 & 15 & 144.35 \\
\hline
\end{tabular}

\section{Modeling}

\subsection{Control volumes}

To create a model of the shallow river system, the Saint-Venant equations will be used. These equations describe the behavior of the river and consists of both mass and momentum balances, and are tricky to solve numerically. The Finite Volume method with staggered grid is common for solving such kinds of problems. The staggered grid is the scheme where the grid for mass balance is shifted with regard to momentum balance's grid as it is shown in Figure 6, where the blue segments (control volumes) on top of the figure is the grid for the mass balance and the skewed red segments below is the grid for the momentum balance.

The level h, volumetric flow rate $\dot{V}$ and their variation along the $x$-axis are shown in Figure 6. Here $x$ is in the interval from zero to $L$ and also is presented as grid $i$ in interval $i=1,2, \ldots, 11$. In addition, the figure shows the variation of pressure $p$ along $x$ or $i$.

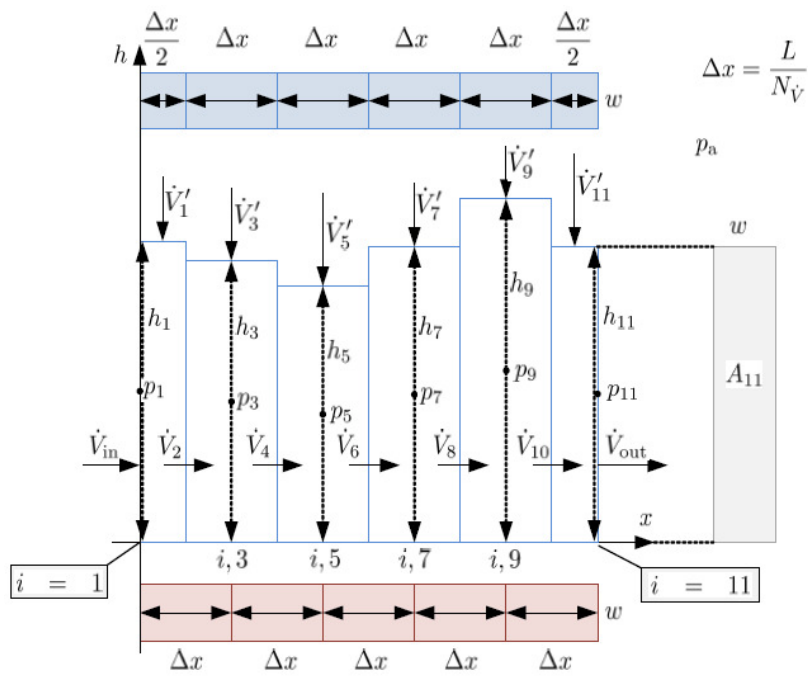

Figure 6. The scheme of Staggered grid (Lie et al., 2013).
As is seen from Figure 6, the number of control volumes for the mass balance/levels $\left(N_{h}\right)$ is one larger than for the momentum balance/volumetric flows $\left(N_{\dot{V}}\right)$. In the figure $N_{\dot{V}}=5$ and each of these segments has length $\Delta x$. For levels, $N_{h}=N_{\dot{V}}+1=6$ and here for the first and last segments, the length is $\frac{\Delta x}{2}$ and all other segments have length $\Delta x$.

In addition, in Figure 7 is shown the slope of river bed $\theta$ and the gravity $g$ vector.

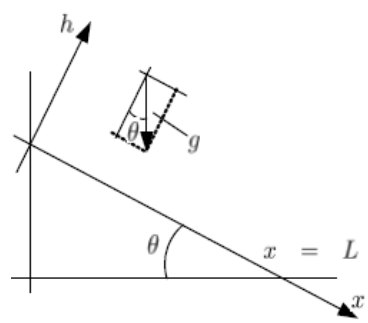

Figure 7. The slope geometry (Lie et al., 2013).

\subsection{Model formulation}

Some simplifying assumptions are introduced for developing the Saint-Venant equations (Lie et al., 2013):

- The run-of-river system is considered as a shallow river, which means that the water level and width of the river is much smaller than the length of the river, and the slope of the river is not too steep. This also means that the depth of the river has little variation. In this case, the hydrostatic pressure approximation can replace the vertical variation of the water motion, and the flow velocity is approximated by the depthaveraged flow velocity (Stelling et al., 2003).

- The fluid is incompressible and the streamline curvature is small. In addition, formulas related to steady flow (e.g. the Manning Formula and the Chézy Formula) can be used to estimate the effect of friction.

- Coriolis force is neglected. Only gravity force is taken into consideration.

Stelling and Duinmeijer studied the staggered conservation scheme for the discretization of the SaintVenant equations in van't Hof et al. (2012). The discretization of the Saint-Venant equations for the mass balance with Finite Volume method results in:

$$
\frac{d h_{i}}{d t}=\frac{\dot{V}_{i-1}-\dot{V}_{i+1}}{w \cdot \Delta x}+\frac{\dot{V}_{i}^{\prime}}{w}
$$

for $i=3,5, \ldots, 2 N_{\dot{V}}-1$. For the first and last level, equation (1) will be as follows: 


$$
\begin{aligned}
\frac{d h_{1}}{d t} & =\frac{\dot{V}_{\text {in }}-\dot{V}_{2}}{w \cdot \frac{\Delta x}{2}}+\frac{\dot{V}_{1}^{\prime}}{w} \\
\frac{d h_{2 N_{\dot{V}}+1}}{d t} & =\frac{\dot{V}_{2 N_{\dot{V}}}-\dot{V}_{\text {out }}}{w \cdot \frac{\Delta x}{2}}+\frac{\dot{V}_{2 N_{\dot{V}}+1}^{\prime}}{w}
\end{aligned}
$$

The discretization of the Saint-Venant equations for the momentum balance with the Finite Volume method result is in:

$$
\begin{aligned}
\frac{d \dot{V}_{i}}{d t}= & \frac{\frac{\dot{M}_{i, i}}{\rho}-\frac{\dot{M}_{o, i}}{\rho}}{\Delta x}+g \cdot \cos \theta \cdot w \cdot \frac{h_{i-1}^{2}-h_{i+1}^{2}}{2 \cdot \Delta x} \\
& +\bar{A}_{i} \cdot g \cdot \sin \theta-\frac{g}{\bar{C}_{i}^{2}} \frac{\bar{\varphi}_{i}}{\bar{A}_{i}^{2}}\left|\dot{V}_{i}\right| \dot{V}_{i}
\end{aligned}
$$

which is valid for $i=2,4, \ldots, 2 N_{\dot{V}}$. In this equation, the momentum input and output flow per density are defined as follows:

$$
\begin{aligned}
& \frac{\dot{M}_{i, i}}{\rho}=\left\{\begin{array}{cc}
\frac{\dot{V}_{i n}}{A_{1}}, & i=2 \\
\frac{\left|\dot{V}_{i-2}\right|}{\bar{A}_{i-2}} \cdot \max \left(\dot{V}_{i-2}, 0\right) & i=4,6, \ldots, 2 N_{\dot{V}}-2 \\
+\frac{\left|\dot{V}_{i+2}\right|}{\bar{A}_{i+2}} \cdot \max \left(-\dot{V}_{i+2}, 0\right), & \\
\frac{\left|\dot{V}_{2 N_{\dot{V}}-2}\right|}{\bar{A}_{i-2}} \cdot \max \left(\dot{V}_{2 N_{\dot{V}}-2}, 0\right), & i=2 N_{\dot{V}}
\end{array}\right. \\
& \frac{\dot{M}_{o, i}}{\rho}=\left\{\begin{array}{cc}
\frac{\dot{V}_{i}^{2}}{\bar{A}_{i}}, & i=2,4, \ldots, 2 N_{\dot{V}}-2 \\
\frac{\dot{V}_{o u t}}{A_{2 N_{\dot{V}}+1}}, & i=2 N_{\dot{V}}
\end{array}\right.
\end{aligned}
$$

Also here, cross sectional area $A$, wetted perimeter $\varphi$ and their averages between neighboring segments $(\bar{A}, \bar{\varphi})$ are defined as:

$$
\begin{gathered}
A_{i}=w \cdot h_{i} \\
\varphi_{i}=w+2 h_{i} \\
\bar{h}_{i}=\frac{h_{i-1}+h_{i+1}}{2} \\
\bar{A}_{i}=\bar{h}_{i} \cdot w \\
\bar{\varphi}_{i}=\frac{\varphi_{i-1}+\varphi_{i+1}}{2}
\end{gathered}
$$

The Chézy friction coefficient $C$, which is defined in relation to Strickler's friction factor $k_{S}$ is shown below:

$$
C_{i}=k_{S} R_{i}^{\frac{1}{6}}
$$

where $R_{i}=\frac{A_{i}}{\varphi_{i}}$ and it is the hydraulic radius.

If it is assumed that $N_{\dot{V}}$ goes to infinity, the model will become as follows:

$$
\begin{gathered}
\frac{\partial h}{\partial t}=-\frac{1}{w} \frac{\partial \dot{V}}{\partial x}+\frac{\dot{V}^{\prime}}{w} \\
\frac{\partial \dot{V}}{d t}=-\frac{\partial}{\partial x}\left(\frac{\dot{V}^{2}}{A}\right)-g \cdot A \cdot \cos \theta \cdot \frac{\partial h}{\partial x} \\
+A \cdot g \cdot \sin \theta-\frac{g}{C^{2}} \frac{\varphi}{A^{2}}|\dot{V}| \dot{V}
\end{gathered}
$$

with boundary conditions:

$$
\begin{aligned}
& \dot{V}_{x=0}=\dot{V}_{\text {in }} \\
& \dot{V}_{x=L}=\dot{V}_{\text {out }}
\end{aligned}
$$

\subsection{Operational data and parameters}

After the run-of-river model is given by the Finite Volume discretization, it is possible to describe it by different elements such as states, inputs, and parameters. The states of the model are as follows:

- $h_{i}$ - the water level along the river, where $i=1,3$, $\ldots, 2 N_{\dot{V}}+1$.

- $\dot{V}_{i}-$ the volumetric flow rate along the river, where $i=2,4, \ldots, 2 N_{\dot{V}}$

The inputs for the model are:

- $\dot{V}_{i n}-$ inlet volumetric flow rate.

- $\dot{V}_{\text {out }}$ - outlet volumetric flow rate.

- $\dot{V}_{i}^{\prime}$ - lateral inflow per length unit, where $i=1,3$, $\ldots, 2 N_{\dot{V}}+1$.

The model parameters are:

- $w$ - width of the river.

- $\theta$ - angle of river slope.

- $\rho$-density of water.

- $g-$ the gravitational acceleration.

- $k_{S}-$ Strickler friction factor.

The values for each model parameters will be specified in Table 2. Also the nominal operating parameters are presented in Table 3.

\subsection{Model simulation and verification}

Some basic simulation is done to verify the model. All parameters are as in Table 2 and Table 3, the simulation is started from steady state, and after $10 \mathrm{~min}$ the inlet volumetric flow rate $\dot{V}_{\text {in }}$ is suddenly changed from the normal value, which is equal $120 \mathrm{~m}^{3} / \mathrm{s}$ (in steady state, all the volumetric flow rates are equal to this value), to $160 \mathrm{~m}^{3} / \mathrm{s}$. This new flow rate lasts for 15 minutes, then the inlet flow rate is reduced back to $120 \mathrm{~m}^{3} / \mathrm{s}$ (as designed in the experiment). There is also some time for 
increase and decrease in the inlet flow rate; this takes 10 seconds. It should be noted that all simulations are done in MATLAB using the "ode23" solver. Here and in the subsequent simulations, the whole river length is divided into 100 nodes, which means that $N_{\dot{V}}=100$ and $\Delta x=50 \mathrm{~m}$. The result of the simulation of the model with constant width and slope is shown in Figure 8 where the top plot shows the water level ahead of the Grønvollfoss dam as a function of time. The bottom plot shows how different volumetric flow rates (for inlet, for 1st, 2nd, 50th, 99th and last 100th segments) change with time.

Table 2. Parameters for run-of-river model.

\begin{tabular}{|l|l|l|l|}
\hline Variable & Value & Unit & Comments \\
\hline$g$ & 9.81 & $\mathrm{~m} / \mathrm{s}^{2}$ & $\begin{array}{l}\text { the gravitational } \\
\text { acceleration }\end{array}$ \\
\hline$\rho$ & 1000 & $\mathrm{k} / \mathrm{m}^{3}$ & density of water \\
\hline$w$ & 166 & $\mathrm{~m}$ & width of the river \\
\hline$H$ & 17.5 & $\mathrm{~m}$ & height of the river \\
\hline$L$ & 5000 & $\mathrm{~m}$ & length of the river \\
\hline$\theta$ & $\sin ^{-1} \frac{H}{L}$ & - & $\begin{array}{l}\text { angle of river } \\
\text { slope }\end{array}$ \\
\hline$k_{S}$ & 20 & $\mathrm{~m}^{1 / 3} / \mathrm{s}$ & $\begin{array}{l}\text { Strickler friction } \\
\text { factor }\end{array}$ \\
\hline
\end{tabular}

Table 3. Nominal operating parameters for run-of-river model.

\begin{tabular}{|l|l|l|l|}
\hline Variable & Value & Unit & Comments \\
\hline$\dot{V}_{\text {in }}$ & 120 & $\mathrm{~m} 3 / \mathrm{s}$ & $\begin{array}{l}\text { inlet volumetric } \\
\text { flow rate }\end{array}$ \\
\hline$\dot{V}_{\text {out }}$ & 120 & $\mathrm{~m} 3 / \mathrm{s}$ & $\begin{array}{l}\text { outlet volumetric } \\
\text { flow rate }\end{array}$ \\
\hline$\dot{V}_{i}^{\prime}$ & 0 & $\mathrm{~m} 3 /(\mathrm{s} \mathrm{m})$ & $\begin{array}{l}\text { lateral inflow per } \\
\text { length unit }\end{array}$ \\
\hline$h(x=L)$ & 19 & $\mathrm{~m}$ & $\begin{array}{l}\text { steady state level } \\
\text { ahead of the dam }\end{array}$ \\
\hline$\dot{V}$ & 120 & $\mathrm{~m} 3 / \mathrm{s}$ & $\begin{array}{l}\text { steady volumetric } \\
\text { flow rate }\end{array}$ \\
\hline
\end{tabular}

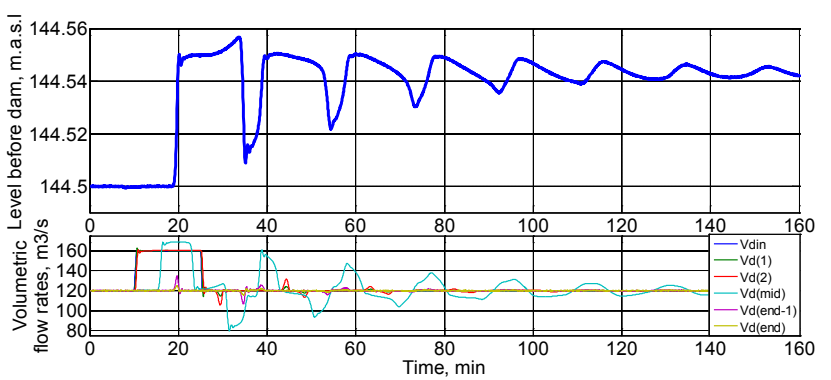

Figure 8. The simulation the model with constant width and slope, $k_{S}=20 \mathrm{~m}^{1 / 3} / \mathrm{s}$.
From Figure 8, the simulation results show that around $10 \mathrm{~min}$ is needed from the change in the inlet flow rate to the water level ahead of the dam starts to increase. Steady state is reached after more than two hours, when the oscillations have decayed. These oscillations describe a wave, which is initiated by the inlet flow jump, and reflections from the Grønvollfoss dam back and forth to Årlifoss. The jump of the inlet flow rate leads to an increase in the water level ahead of the dam of around $4 \mathrm{~cm}$. This increase is also seen from results of the water level along the whole river, as is shown in Figure 9.

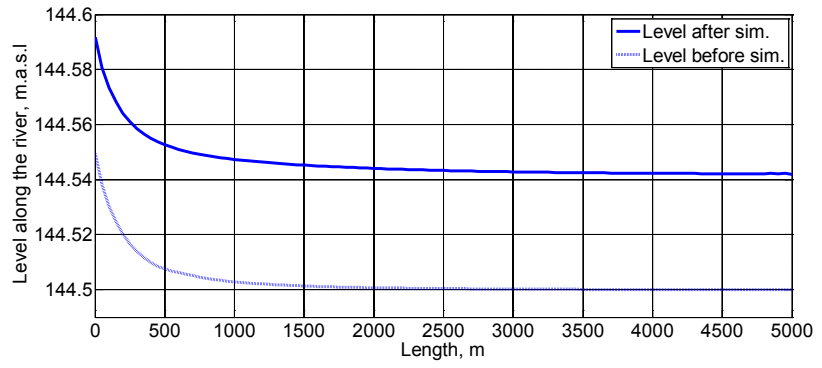

Figure 9. The water level along the river before and after jump of the inlet flow rate.

\section{Model fitting}

\subsection{Experimental data}

The experimental results of power production in the Årlifoss power plant are shown in Figure 10. Here, it is seen that before the experiment was started, the power production was around $18 \mathrm{MW}$ and at the time 10:04:45 AM the production was increased to $22.5 \mathrm{MW}$ within a time lapse of 30 seconds. The new value of power production was kept stable for around 15 minutes and then at 10:19:55 AM it was decreased to the initial value, around $18 \mathrm{MW}$. This decrease took around 20 seconds. These values of power production $18 \mathrm{MW}$ and 22.5 MW correspond to approximately 120 and 160 $\mathrm{m} 3 / \mathrm{s}$ of volumetric flow rate respectively.

The water level just after the Årlifoss power plant is also measured, but unfortunately, the water level can not be logged and can only be observed from the screen of the monitoring panel in the Årlifoss power plant, where the results from the level sensor is presented without any filtering. Nevertheless, the observation of this level shows that it increases during the jump of inlet flow rate with around $15 \mathrm{~cm}$. After decreasing the flow in the Årlifoss power plant back to $120 \mathrm{~m} 3 / \mathrm{s}$, this water level also decreases to the previous level (around 145.7 m.a.s.l.). 


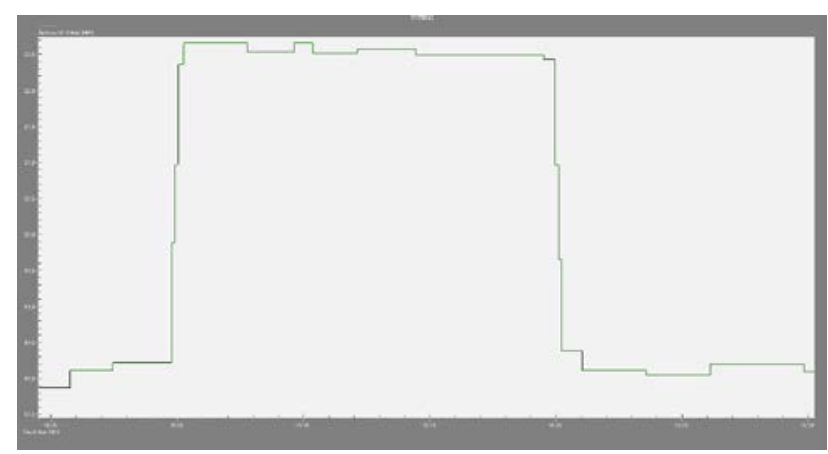

Figure 10. Measured power production in the Årlifoss power plant during experiment.

The results of the experiment for the water level ahead of the Grønvollfoss dam are presented in Figure 11. Here the time 0 min means the actual time 9:54:45 AM of the experiment day. The increase from 120 to $160 \mathrm{~m} 3 / \mathrm{s}$ of inlet flow rate starts at 10:04:45 AM, which is after $10 \mathrm{~min}$ in the figure. Then after around 15 minutes, at 10:19:55, the inlet flow decreases to the original $120 \mathrm{~m} 3 / \mathrm{s}$, which is after $25 \mathrm{~min}$ is the figure. As it is shown in the figure, the water level ahead of the Grønvollfoss dam starts increasing at a time around 20 min, which is 10 minutes after the inlet flow rate was increased. Then oscillations are seen in the water level ahead of the dam. These oscillations describe a wave, which is initiated by the inlet flow jump, and reflections from the Grønvollfoss dam back and forth to Årlifoss. This process continues with damping until a new steady state is reached. The period time of each oscillation is around 21 minutes and the steady state is reached after more than 80 minutes. The jump of the inlet flow rate leads to an increase in the water level ahead of the dam of around $3 \mathrm{~cm}$.

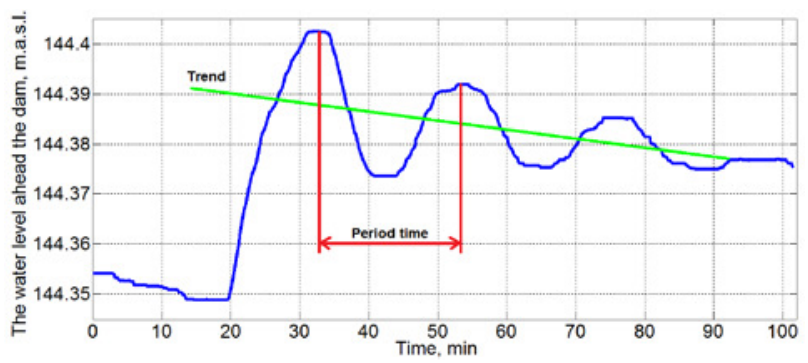

Figure 11. The plot of experimental result of the water level ahead of the Grønvollfoss dam.

Here, from Figure 11, it should be also noted that the trend of oscillations goes a little bit down (the average of maximum and minimum values of one oscillation becomes lower for every next oscillation). This trend can be caused by an outlet flow rate which is a little bit bigger than the inlet flow rate to the system, e.g. $\dot{V}_{\text {in }}=$ $120 \mathrm{~m}^{3} / \mathrm{s}$ but $\dot{V}_{\text {out }}=121 \mathrm{~m}^{3} / \mathrm{s}$.

\subsection{Manual tuning of the model}

Now the model should be tuned to fit the experimental data. We start with changing the Strickler friction factor, continue with type of slope or width behavior (constant or non-constant width and slope) and also include the river length. It should be mentioned that decreasing or increasing the Strickler friction factor or the river length could compensate the approximations with the width and slope, which effectively introduce reflection of waves, which can be interpreted as increased friction. That is why the observed Strickler factor (from the literature: in range $20-80 \mathrm{~m}^{1 / 3} / \mathrm{s}$ ) can be less than 20 $\mathrm{m}^{1 / 3} / \mathrm{s}$ and the river length can be more than $5 \mathrm{~km}$.

First of all, the model with constant width and slope is tuned by changing the Strickler factor, due to this model being the simplest, which is beneficial for use in model based control. All the other parameters are used as during previous simulations, but the steady state water level ahead of the dam is reduced to 144.35 m.a.s.l. as it was in experiment. The time of increasing and decreasing the inlet volumetric flow rate should be also changed to 30 seconds for increasing and 20 seconds for decreasing as it is seen from experimental data (see Figure 10). Also as in previous simulations, the number of nodes is the same and equal to 100 . Simulations are done in MATLAB using the "ode23" solver. The result of comparing the water level ahead of the Grønvollfoss dam from the constant model with chosen Strickler factor equal to $16 \mathrm{~m}^{1 / 3} / \mathrm{s}$ and the experimental results is shown in Figure 12.

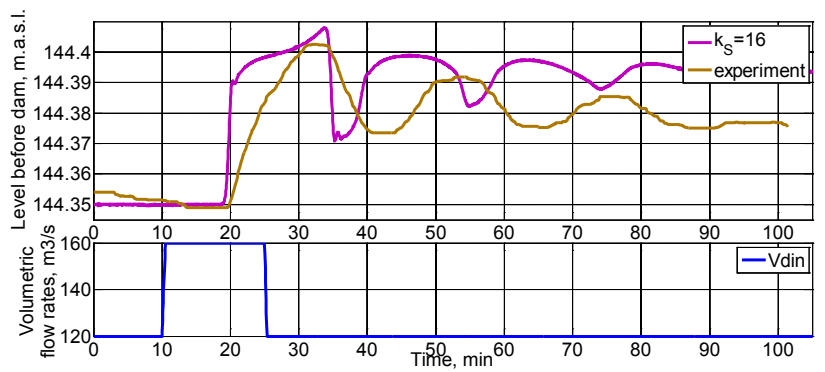

Figure 12. Comparison of the tuned model with constant width and slope against experimental result.

Figure 12 shows that the real data from experiment is not really the same as the model result, especially the period time of the oscillations, which is longer for the experiment, and the level increasing, which is around 4 $\mathrm{cm}$ in the simulation result as opposed to around $3 \mathrm{~cm}$ in the experimental data. The benefits are that the amplitude of oscillations and the time of reaching the wave dam is approximately the same. One more disadvantage is that the model result of water level after the Årlifoss power plant does not match the experimental data (the difference is more than $1 \mathrm{~m}$ ), where this level should be higher (around 145.7 m.a.s.l.) and should not increase a lot after the inlet flow rate jump was finished. The steady state level along the river is in Figure 13. 


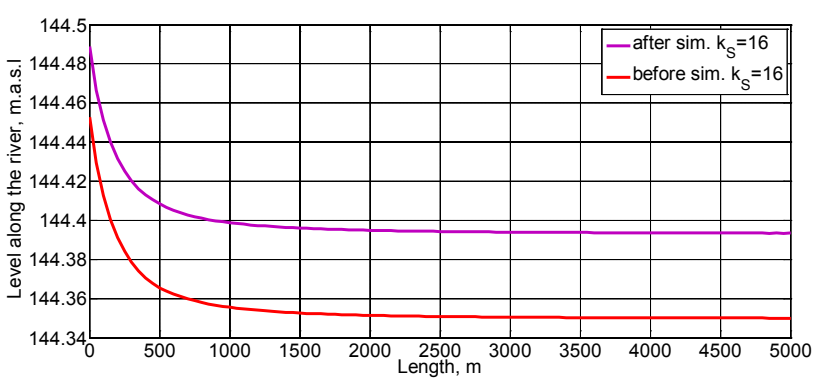

Figure 13. The steady water level along the river before and after jump of the inlet flow rate.

Next, the model with non-constant slope and width is tuned with experimental data. This model was tuned using the Strickler factor, and the best fit was achieved with Strickler factor equal to $14 \mathrm{~m}^{1 / 3} / \mathrm{s}$. The comparison between varying width/slope model after tuning of the Strickler constant, with experiment results is shown in Figure 14. The steady river level computed from this tuned model are shown in Figure 15.

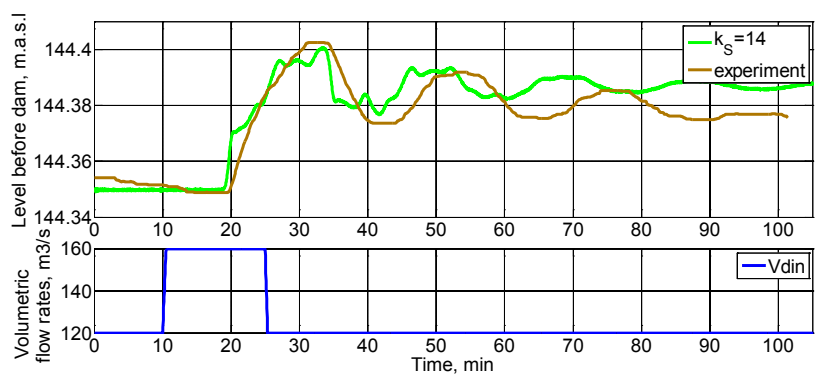

Figure 14. Comparison of the tuned model with varying width and slope against experimental result.

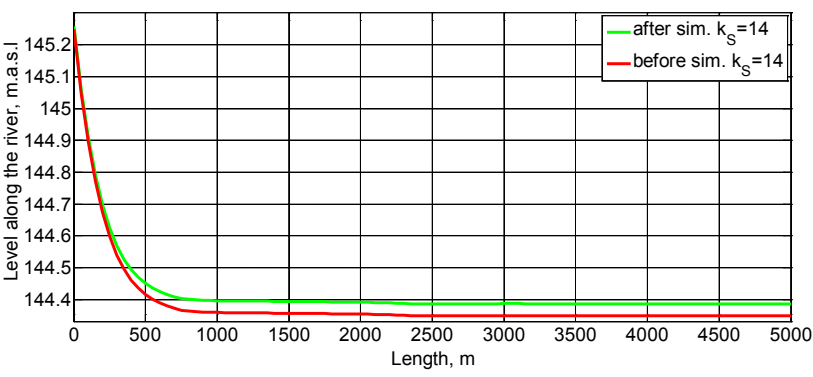

Figure 15. The steady water level along the river before and after jump of the inlet flow rate.

Figure 14 and Figure 15 show that in comparison to experimental data, the model results are quite good and match the real points better than the model with constant slope/width. There are still the same deficiencies as in the model with constant slope and width:

- The oscillation period is still shorter than in the real results, but longer that in the constant model;

- The level increase is still higher from the model results than in experiment, but here this difference is around $0.5 \mathrm{~cm}$, which is better than in the constant model;

- The water level after the Årlifoss power plant is still lower than expected from the real data, but here it is around $0.5 \mathrm{~m}$ difference (145.7-145.2 m.a.s.1.), which is better than in the model with constant slope/width.
And also one positive thing is that this water level after the Årlifoss plant comes back to the initial value after the inlet flow rate jump was finished.

Also after analysis the experimental results, it was seen that the trend of oscillations goes a little bit down (see Figure 11), so it is in interest to try also to make small difference between inlet and outlet volumetric flow rates. That is why the outlet flow rate is increased on $1 \mathrm{~m}^{3} / \mathrm{s}$ to $121 \mathrm{~m}^{3} / \mathrm{s}$. The results of the water level ahead of the dam in this case are shown in Figure 16 for the model with constant slope and width, and in Figure 17 for the model with non-constant slope and width.

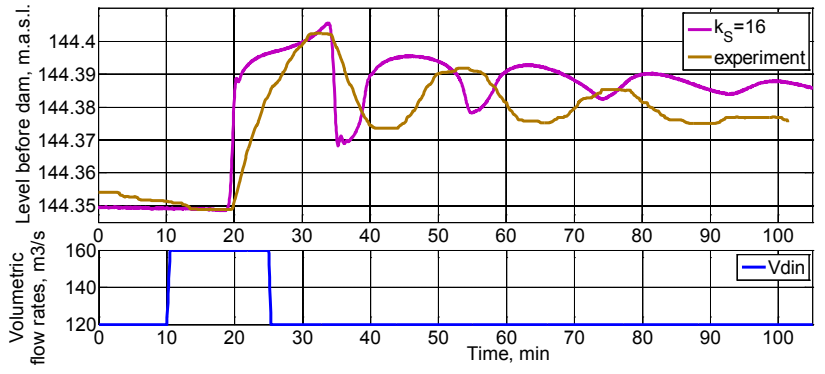

Figure 16. Validation of the model with constant width and slope with the experimental results, when $\dot{V}_{\text {out }}=121$ $\mathrm{m}^{3} / \mathrm{s}$.

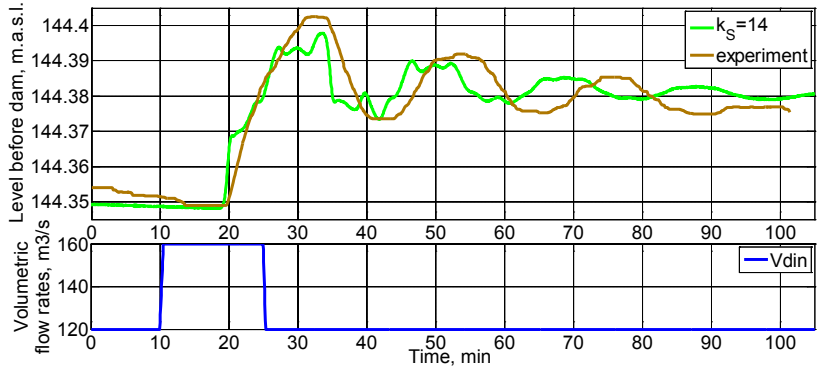

Figure 17. Validation of the model with varying width and slope with the experimental results, when $\dot{V}_{\text {out }}=121$ $\mathrm{m}^{3} / \mathrm{s}$.

As it is seen from Figure 16, the increase of the outlet volumetric flow rate does not show much better results for the constant width/slope model.

But from Figure 17 this increase in the outlet volumetric flow rate of just $1 \mathrm{~m} 3 / \mathrm{s}$ make the simulation results fit better the experimental data for the varying width/slope model. In particular, this is seen at the new level ahead of the dam after the jump of inlet flow rate. But simulations results in this figure still show too short oscillation period.

The simplest way to adjust the oscillation period is to change the length of the river. Although this makes the model somewhat unphysical, changing the length can be thought of as compensating for other model simplifications. The best fit for the constant width/slope model is found with a length of $6.3 \mathrm{~km}$, which is shown in Figure 18. Here, the water level ahead of the dam from the model fits the experimental data quite well. Still there is mismatch with the water level just after the Årlifoss dam, however this water level is of less interest 
and the main point should be given to the water level ahead of Grønvollfoss.

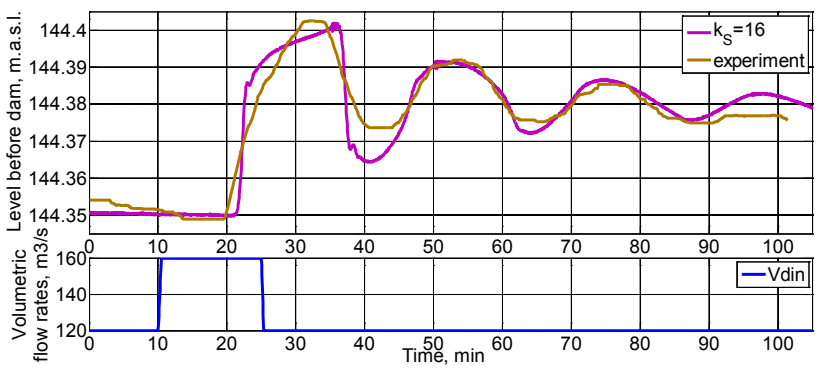

Figure 18. Validation of the constant width/slope model with experimental results, when $\dot{V}_{\text {out }}=121 \mathrm{~m}^{3} / \mathrm{s}$ and length of river equal $6300 \mathrm{~m}$.

The results of the model with varying slope and width for the same river length equal to $6.3 \mathrm{~km}$ are shown in Figure 19. Here it can be seen that the increase of the river length makes this model fit the experimental data better relating to the oscillation period, but worse the water level.

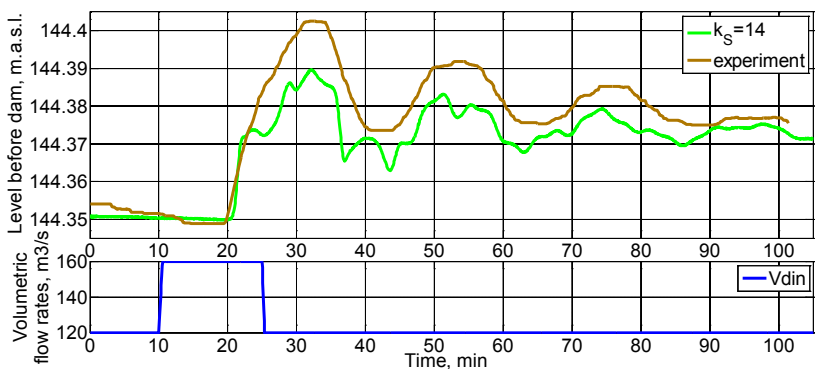

Figure 19. Validation of the model with varying slope and width with experimental results, when $\dot{V}_{\text {out }}=121$ $\mathrm{m}^{3} / \mathrm{s}$ and length of river equal $6300 \mathrm{~m}$.

From all this tuning we can make the conclusion that the geometry of the river is very important for these models. However, the geometry information can be simplified by tuning the friction term with the Strickler factor, the river length or the value of constant width.

\subsection{Least squares model fitting}

After basic model validation with trial and error is done, the results from the model with constant slope and width looks pretty well. That is why, the least squares error algorithm is used to tune the Strickler factor, the river length and the value of the constant width of the river for this simple model (constant width/slope).

The least squares error algorithm is nothing but just an optimization problem for minimization sum of squares error between the model and the experimental results of the water level ahead of the Grønvollfoss dam. This algorithm is developed in MATLAB using the MultiStart function, which is solved the optimization problem from different start points, due to this problem has many local solutions. These start points are specified as a vector, which include different combinations of the Strickler factor, the river length and width based on previous studying. And that is why the first initial value for this optimization problem are taken from the best fitting results of the model from previous model validation part: $k_{S, 0}=16 \mathrm{~m}^{1 / 3} / \mathrm{s}, L_{0}=6.3 \mathrm{~km}$ and $w_{0}=$ $166 \mathrm{~m}$.

The vectors of results for the water level ahead of the dam from the model and experiment should have the same size. That is why, the model will be simulated with time step equal to $5 \mathrm{sec}$. and for the time equal to 6085 sec. (as in the results from experiment). The error will be taken not for the whole simulated time length, but only from time equal to $20 \mathrm{~min}$. when the water level ahead of the dam starts to increase due to the jump of the inlet flow rate (see Figure 18).

The results of the least squares error algorithm are presented in Figure 20, where the sum of squares errors is equal to 0.0121 and the optimal values for the Strickler factor, the river length and width are $k_{S}=$ $13.513 \mathrm{~m}^{1 / 3} / \mathrm{s}, L=6300.09 \mathrm{~m}$ and $w=161.5 \mathrm{~m}$. Here the inlet flow is shown in the bottom plot and the outlet volumetric flow is $\dot{V}_{\text {out }}=121 \mathrm{~m}^{3} / \mathrm{s}$.

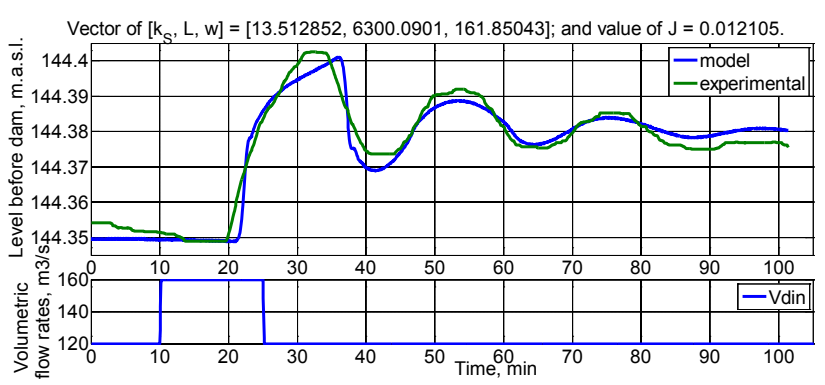

Figure 20. The results of the least squares model fitting.

It should be noted that the sum of squares errors for the best fitting results of the model from previous model validation part is equal to $0.0207\left(k_{S}=16 \mathrm{~m}^{1 / 3} / \mathrm{s}, L=6.3\right.$ $\mathrm{km}$ and $w=166 \mathrm{~m})$. Therefore, the least squares error algorithm helps to find the parameters that leads to better model fitting.

\subsection{Further testing of model}

Next, the number of nodes is decreased to just 20 to make the model as fast as possible. And results of simulating this model are compared with the results from the model with 100 nodes and with experimental data, Figure 21

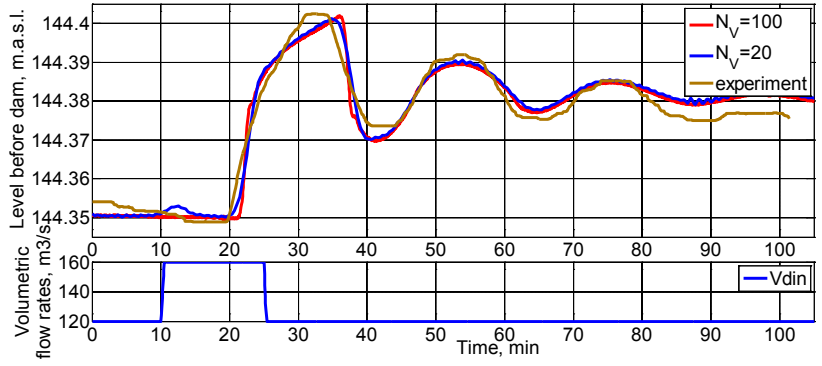

Figure 21. Comparing the results depends on the number of nodes. 
Figure 21 shows that there are almost no difference between results from the model with 100 nodes and 20 nodes. Although some accuracy is lost with fewer nodes, the simulation time is 6-7 times less for the model with 20 compartments.

\section{Discussion and conclusions}

In this paper, the use of the Saint-Venant equations for a run-of-river system has been explored. The Finite Volume method with staggered grid was used to discretize and solve the Saint-Venant equations. The substantially new geometry of the river was provided by Skagerak Energi, and also an experiment on the system was done to compare the model results with reality.

The effect of varying slope and width on the model was also studied. Using this possibility of slope and width variation and also with changing the Strickler factor and the river length, the model was tuned against the experimental data. After this tuning, the model fitted the experimental data reasonably well.

The validation shows that the geometry of the river is very important for these models. However, the geometry information can be simplified by tuning the friction term with the Strickler factor, the river length or the value of constant width.

\section{Future work}

When the run-of-river model is tuned against experimental results, it can be used to design model based control for the Grønvollfoss power plant. It is possible to linearize the model for use in advanced control, but it is also possible to use the non-linear model directly.

\section{References}

De Schutter, B. and Scattolini, R. Introduction to the special issue on hierarchical and distributed model predictive control. Journal of Process Control, 2011. 21(5): pp. $683-$ 684.

Farina, M., Ferrari-Trecate, G., Romani, C., Scattolini, R. Moving horizon estimation for distributed nonlinear systems with application to cascade river reaches. Journal of Process Control, 2011. 21(5): pp. 767-774.

Johansen A. O. Implementation and test of a fifth order Central WENO scheme for solving hyperbolic balance laws. Added Values P/S, Lysholt Alle 10, Dk-7100, Vejle, Denmark, February 2015.

Johansen, A. O., Elmegaard B. and Sørensen, J. N., 2012a, Implementation and test of a higher order hybrid solver for hyperbolic and parabolic balance laws. International Journal for Computers \& Mathematics with Applications, $1-32$.

Lie, B., Ruan, Y., and Andreassen, I. (2013): Modeling for control of run-of-river power plant". Proceedings, 54th International Conference of Scandinavian Simulation Society (SIMS 2013), October 16-17 2013, Bergen, Norway.
Stelling, G. S. and Duinmeijer, S. P. A. A staggered conservative scheme for every Froude number in rapidly varied shallow water flows. International Journal for Numerical Methods in Fluids, 2003. 43(12): pp. 1329-1354.

van't Hof, B. and Veldman, A.E. Mass, momentum and energy conserving (MaMEC) discretizations on general grids for the compressible Euler and shallow water equations. Journal of Computational Physics, 2012.

Xu, M., Negenborn, R.R., van Overloop, P.J., van de Giesen, N.C. De Saint-Venant equations-based model assessment in model predictive control of open channel flow. Advances in Water Resources, 2012. 